\title{
América Latina: Modernidad, cuestión colonial y cultura de la resistencia
}

\section{Latin America: Modernity, the Colonial Issue and the Culture of Resistance}

\author{
Andrés Mora Ramírez \\ Instituto de Estudios Latinoamericanos \\ Universidad Nacional, Costa Rica \\ andres.mora.ramirez@una.cr
}

\begin{abstract}
Resumen
Este ensayo desarrolla una reflexión sobre algunos de los abordajes teóricos a partir de los cuales distintas corrientes de investigación se han aproximado al problema de la continuidad colonial en América Latina. El punto de partida es la discusión sobre la pertinencia del análisis poscolonial para el estudio de las formaciones sociales de nuestra región. Para ello, se presenta un acercamiento al estado actual de los debates sobre los alcances, limitaciones y conflictos que enfrenta este campo de estudio, y luego, se argumenta sobre la necesidad de enriquecer sus enfoques desde un posicionamiento latinoamericanista que favorezca la construcción de rutas de investigación y perspectivas de conocimiento no eurocéntricas, situadas en nuestros contexto y sin complejos de inferioridad para defender el lugar tradicionalmente subordinado pero rebelde del nosotros latinoamericano.
\end{abstract}

Palabras clave: Modernidad occidental, colonialidad, estudios poscoloniales, pensamiento latinoamericano, cultura de la resistencia. 


\begin{abstract}
This essay develops a reflection about some theoretical approaches upon which several lines of research have approximated to the problem of the colonial continuity in Latin America. The starting point is the discussion about the relevance of post-colonial analysis for the study of the social formations of our region. For this purpose an approximation is made to the state of the debates regarding the scope, limitations and conflicts that this field of study faces. Next it is argued the pertinence of enhance its approaches from a Latin Americanist stance that favors the construction of routes of research and perspectives of non-Eurocentric knowledge, located in our own context, and without an inferiority complex in order to defend the traditionally subordinated but rebellious place of the Latinamerican-We.
\end{abstract}

Keywords: Western Modernity, coloniality; postcolonial studies, latin american thought, culture of resistanc

La interpretación de nuestra realidad con esquemas ajenos sólo contribuye a hacernos cada vez más desconocidos, cada vez menos libres, cada vez más solitarios. Gabriel García Márquez (1982, p 3).

I.

$\mathbf{E}$ n 1891, en su ensayo Nuestra América, considerado uno de los manifiestos fundacionales del pensamiento crítico latinoamericano, José Martí presentó una esclarecida argumentación sobre el devenir de América Latina, de sus pueblos y sus culturas, en los prolegómenos de la primera modernización liberal de finales del siglo XIX y principios del $\mathrm{XX}$. En su texto, que ofrece claves de incalculable valor para el estudio y la interpretación de la realidad latinoamericana, Martí (en Hart-Dávalos, 2000) aborda las contradicciones y tensiones que advertía en el origen de muchos de los problemas de nuestras dolorosas repúblicas: nos mirábamos al espejo con los ojos de Europa, los ojos del amo, y encontrábamos un reflejo deforme en el que no nos reconocíamos; éramos una máscara-decía- "con los calzones de Inglaterra, el chaleco parisiense, el chaquetón de Norteamérica y la montera de España", e insistía: "éramos charreteras y togas, en países que venían al mundo con la alpargata en los pies y la vincha en la cabeza" (p. 209); para organizar nuestras sociedades, asumimos formas y maneras que no correspondían a la particularidad de nuestra historia y a la composición "singular y violenta" de nuestros pueblos, a los que no se podía regir "con leyes heredadas de cuatro siglos de práctica libre en los Estados Unidos, de 19 siglos de monarquía en Francia" (p. 204). Y sentenciaba: "La colonia continuó viviendo en la república" (p. 208).

En 1982, al recibir el premio Nobel de Literatura de la Academia Sueca, Gabriel García Márquez ofreció un memorable discurso en el que, a partir del contrapunteo 
de las fantasías del imaginario europeo que se encuentran en la base de la invención de América, con los dolorosos pasajes de la historia latinoamericana del siglo $\mathrm{XX}$-que a veces parecen evocaciones del realismo mágico-, lanzó una vigorosa afirmación: "América Latina no quiere ni tiene por qué ser un alfil sin albedrío, ni tiene nada de quimérico que sus designios de independencia y originalidad se conviertan en una aspiración occidental" (García-Márquez, 1982, p. 3); y acto seguido interpeló a la audiencia con una pregunta cuyos ecos resuenan en nuestro pasado, como desafiando el oprobioso legado cultural del eurocentrismo, y se proyectan hacia el futuro con acentos utópicos:

¿Por qué la originalidad que se nos admite sin reservas en la literatura se nos niega con toda clase de suspicacias en nuestras tentativas tan difíciles de cambio social? ¿Por qué pensar que la justicia social que los europeos de avanzada tratan de imponer en sus países no puede también ser un objetivo latinoamericano con métodos distintos en condiciones diferentes? (GarcíaMárquez, 1982, p. 3)

A casi un siglo de distancia temporal, pero cercanos en sus preocupaciones intelectuales, Martí y García Márquez coincidieron en plantear la misma cuestión de fondo: que la continuidad del problema colonial -yugo, huella y herida abierta-, en la trama compleja de sus distintas expresiones, es el nudo asfixiante y todavía por desatar en la larga lucha por la liberación de nuestra América. Por eso, la vindicación que ambos realizan de la especificidad latinoamericana, sin pretensiones de falsa universalidad ni de violencia epistémica, así como su alegato en defensa de un pensamiento situado y propio como principio de la praxis emancipadora, conservan su validez y vigencia ahora que nos adentramos en el siglo XXI, por lo demás turbulento y desafiante.

Con esa premisa, en este ensayo nos proponemos reflexionar precisamente sobre algunos de los abordajes teóricos a partir de los cuales distintas corrientes de investigación se han aproximado al problema de la continuidad colonial en América Latina. El punto de partida será la discusión sobre la pertinencia del análisis poscolonial, que encontró espacios de desarrollo principalmente en las academias británica y estadounidense (¿academias imperiales?), y las implicaciones históricas, culturales, económicas y políticas que esto tendría para el estudio de las formaciones sociales de nuestra región.

Presentaremos un acercamiento al estado actual de los debates sobre los alcances, limitaciones y conflictos que enfrenta este campo de estudio, y luego, argumentaremos sobre la necesidad de enriquecer sus enfoques desde un posicionamiento latinoamericanista que favorezca la construcción de rutas de investigación y perspectivas de conocimiento no eurocéntricas, situadas en nuestros contexto y sin complejos de inferioridad para defender el lugar tradicionalmente subordinado pero rebelde del nosotros latinoamericano.

\section{II.}

La reflexión sobre la teoría y la crítica poscolonial nos acerca a un campo del saber que hoy enfrenta una suerte de crisis, 
a saber, la que imponen sus propias limitaciones epistemológicas para aprehender la complejidad del objeto de estudio -la cuestión colonial y el imperialismo, sus huellas y legados en las sociedades que emergieron del proceso de descolonización de la segunda mitad del siglo XX-, y por las lógicas de la geopolítica del conocimiento en las que se ha inscrito su desarrollo científico. En cualquier caso, el campo abierto a la polémica y los debates que en él se libran arrojan luz sobre sus alcances y, al mismo tiempo, sobre sus silencios (que, por lo demás, son característicos del paradigma científico dominante y su tendencia a la fragmentación de los saberes y la producción de ausencias).

Impulsada inicialmente por intelectuales de países colonizados de Asia y África, y en parte del Caribe anglófono, que migraron a la metrópoli colonial y lograron insertarse en las academias noratlánticas, la teoría poscolonial adquiere mayor visibilidad o presencia hacia la década de 1980 desde el ámbito de los estudios culturales, linguísticos y literarios, privilegiando, en ellos, "la exégesis textual y las prácticas performativas para analizar los sistemas de representación y los procesos identitarios" (Santos, 2009, p. 277) en contextos sociales marcados por el colonialismo y, en general, por las relaciones desiguales entre el Norte y el Sur. Su genealogía epistemológica se entrelaza al postestructuralismo francés, la teoría crítica europea y, en general, al posmodernismo finisecular en el que, en alguna medida, ha quedado entrampado, al decir de Walter Mignolo (2007, p. 26).

En los estudios poscoloniales, se asume la tesis de que es desde los márgenes o las periferias donde "las estructuras de poder y de saber son más visibles", por lo que se interesan en "problematizar quién produce el conocimiento, en qué contexto lo produce y para quién lo produce" (Santos, 2009, p. 340); para ello se adentran en la deconstrucción de "la narrativa colonial, escrita por el colonizador, y procuran sustituirla por narrativas escritas desde el punto del vista del colonizado" (Santos, 2009, p. 277).

Para Boaventura de Sousa (2009, pp. 278283), el poscolonialismo ha tenido impacto en el análisis de las relaciones imperiales modernas (los trabajos pioneros de Fanon, y más tarde los de Edward Said, Stuart Hall, Partha Chatterjee, Gayatari Spivak, entre otros estudios así lo demuestran), y logró abrir espacios, por ejemplo, para "la presencia y la voz del crítico poscolonial". Muchos de sus ejes temáticos articuladores contribuyen a repensar la posición del intelectual y de la crítica "de modo que puedan interrumpir eficazmente los discursos hegemónicos occidentales"; al desvelamiento de la ambivalencia de los regímenes identitarios de construcción de la diferencia entre el yo sujeto colonizador y el otro sujeto colonizado, de los migrantes y los sujetos de la diáspora; asimismo, al cuestionamiento de la idea hegemónica de nación y los nacionalismos, en general, en tanto presuponen "una cierta homogeneidad cultural, basada en una identidad forjada a partir de un conflicto".

Sandro Mezzadra (2008, pp. 16-17), por su parte, reivindica los estudios poscoloniales en tanto los considera "como uno de los archivos fundamentales de los que nutrirse para una comprensión crítica de 
nuestro presente", y para una lectura problematizadora de la modernidad, en tanto la historia global "debe ahora leerse a partir de una pluralidad de lugares y de experiencias, en el cruce entre una multiplicidad de miradas que desestabiliza y descentra toda narración eurocéntrica". Esa diversidad encubierta tradicionalmente por las "grandilocuentes narraciones imperiales", como sostenía Stuart Hall (2008, p. 128), le permite al análisis poscolonial reinterpretar "la colonización como parte de un proceso global esencialmente transnacional y transcultural", que se opone a la visión más restringida "del 'aquí' y del 'allí', del 'entonces' y el 'ahora', del 'en nuestro país' y 'en el extranjero'. En este contexto, 'global' no quiere decir universal, pero tampoco es especifico de una nación o sociedad".

Ahora bien, en la otra cara del debate se identifican posiciones que discrepan sobre el rumbo seguido por los estudios poscoloniales. Es el caso de Ella Shohat (2008, p. 111), la crítica cultural iraquí, quien considera que "el término postcolonial porta consigo la insinuación de que el colonialismo es ahora una cuestión del pasado, subestimando las deformadoras huellas económicas, políticas y culturales que el colonialismo ha dejado en el presente" lo que implica una limitación, ya que dicho término pierde fuerza como significante frente a las actuales tensiones geopolíticas, por lo que llegaría "pertrechado con pocas evocaciones de las relaciones de poder contemporáneas".

Por su parte, Gayatari Spivak (2015, p. 13), la intelectual india nacida en Calcuta bajo el colonialismo británico, y una de las principales referentes del campo poscolonial, en un vigoroso ejercicio de crítica, no duda en señalar que "los estudios poscoloniales, al conmemorar involuntariamente un objeto perdido, pueden convertirse en una coartada, a no ser que coloquen tal objeto dentro de un marco general"; Spivak entiende que centrar el análisis "sólo en la representación de los colonizados o en el tema de las colonias" podría resultar funcional a la reproducción de los saberes neocoloniales dominantes, "colocando el colonialismo/imperialismo a salvo en el pasado y/o [sic] sugiriendo una línea continua desde aquel pasado hasta nuestro presente", de donde se deriva el riesgo de convertir el enfoque poscolonial "en un guetto subdisciplinario".

En esta misma línea, Santos (2009, pp. 288-289) considera que un aspecto a discutir en relación con el análisis poscolonial es su tendencia a prescindir de la economía política en el estudio de la cultura o del discurso colonial, lo que llevaría a caer en "silencios estridentes" sobre problemáticas de fondo. Para el sociólogo portugués, esto conlleva el riesgo de situar en otro lugar la lógica binaria propia del colonialismo moderno, pasando, por ejemplo, de las dicotomías colonia/metrópoli o ellos/nosotros, a otra definida como colonial/poscolonial que podría conferirle al colonialismo "el prestigio de marca predominante de la historia"; o bien, que el uso del prefijo pos induzca a pensar en la idea de ruptura con el colonialismo, en lugar de su continuidad, deslocalizando de esta forma la persistencia de sus efectos. De tal suerte, el "descuido respecto del neocolonialismo es una de las limitaciones más incapacitantes del poscolonialismo", toda 
vez que pasa de largo sobre las transformaciones, crisis y adaptaciones del capitalismo que "vienen a crear o a profundizar nuevas formas de neocolonialismo". Frente a esto, Santos (2009, p. 288) propone un poscolonialismo crítico del posmodernismo, que coloque en el centro de anális las relaciones asimétricas de poder propias de los contextos (neo)coloniales, y permita acercarse a la comprensión de elementos y procesos característicos de la modernidad occidental, que se fundan en el desarrollo del capitalismo -más que como un sistema económico, como un avasallante modelo civilizatorio- articulado "con otras relaciones de poder, tales como la explotación de clase, el sexismo y el racismo".

Esos silencios estridentes, sobre los que previene Santos, también son identificados por Mignolo (2011, p. 157) en su balance de la crítica y la teoría poscolonial, en el que hace incapié en la geopolítica de la producción del conocimiento en un campo que ha estado dominado fundamentalmente -aunque no de un modo exclusivo- por "intelectuales que escribían en inglés y desde el entorno del Imperio británico y sus antiguas colonias (Australia, Nueva Zelanda, India)", en una dinámica académica en la que "la totalidad de las Américas, incluyendo el Caribe, el norte de África y, casi siempre, el África subsahariana quedaban fuera del cuadro", con lo que sus enfoques podrían perder de vista el escenario geohistórico más amplio en el que se inscriben las historias, experiencias y problemas de los otros condenados de la tierra. Para este autor, lo poscolonial, entendido desde esta óptica restringida y en algún sentido excluyente, puede derivar en usos ambiguos, peligrosos y confusos: en particular, cuando el término pos "se emplea como una directriz teórica más y se generaliza utilizándose en contra de las prácticas de oposición llevadas a cabo por parte de la gente de color, los intelectuales del Tercer Mundo y los grupos étnicos en la academia", o bien, cuando "expresiones como hibridación, meztizaje, especio-inter-medio y otras equivalentes se convierten en objeto de reflexión y crítica", al sugerir una "discontinuidad entre la configuración colonial del objeto o sujeto de estudio y la posición poscolonial del lugar desde el que se desarrolla la teorización" (Mignolo, 2011, pp.160-161).

Una mirada complementaria a esta arista de la discusión nos la ofrece Fernando Coronil (2000, pp. 87-88), para quien, más que los silencios, son las ausencias las que ponen en jaque a la la teoría poscolonial; en su opinión, resulta llamativo que el trabajo académico en los centros metropolitanos aborde solo de manera tangencial el fenómeno de la colonización europea de las Américas, que "involucró a España, Portugal, Francia, Holanda e Inglaterra y fijó parámetros para su expansión posterior en Asia y África"; más grave aún, sostiene que esta exclusión de lo latinoamericano y caribeño se expresa, además, en "una notable ausencia del imperialismo en los estudios postcoloniales, asunto central para los pensadores latinoamericanos, quienes desde la independencia en el siglo diecinueve han prestado especial atención a las formas persistentes de sometimiento imperial postcolonial". Y concluye que tales ausencias "dicen mucho sobre las políticas del conocimiento occidental e invitan a explorar la manera como la teoría se difunde y a discernir cómo se establecen 
nuevas modalidades de colonización del conocimiento en diferentes regiones y disciplinas académicas".

\section{III.}

Como toda disciplina científica, el análisis poscolonial no puede ir más allá de sus alcances y limitaciones, a las que nos hemos referido ya, sin confrontar las lógicas de construcción del conocimiento y desafiar las relaciones de poder que son constitutivas de su contexto de producción (el de las academias imperiales), y de los factores que incidieron en su propio desarrollo histórico.

En ese sentido, hay quienes evalúan con más severidad la teoría poscolonial, como Garbe y Quintero (16 de noviembre, 2004, párr. 11), en tanto consideran que "no le es posible conceptualizar la modernidad, el eurocentrismo y la geocultura independientemente del colonialismo inglés y francés", lo que lleva a que privilegie en sus análisis "las dimensiones cultural, epistémica y discursiva" de esas experiencias coloniales, descuidando otras y obviando sus manifestaciones contemporáneas.

No obstante, desde la ecología de saberes, nos parece más apropiado buscar puntos de encuentro y caminos de ampliación del horizonte teórico y metodológico en el que se han inscrito los estudios poscoloniales para profundizar en la comprensión de su objeto de estudio, lejos de involucrarnos en disquisiciones académicas descalificadoras que, a la larga, pudieran llevarnos a reproducir la violencia eurocéntrica del colonialismo.

Una actitud epistemológica más constructiva nos invita a nutrir el análisis de la cuestión colonial con los aportes del grupo de investigación Modernidad/colonialidad, integrado por intelectuales latinoamericanos en el exilio o desde sus espacios de trabajo en academias del Norte. A partir de su interés por las oposiciones y rupturas con el eurocentrismo que se articulan desde las resistencias y emancipaciones del Sur, este grupo ha traído a la discusión el enfoque de decolonialidad como un recurso que, al decir de Santiago Castro-Gómez y Ramón Grosfoguel (2007, p. 13), permite ver más allá de las suposiciones de los estudios poscoloniales anglosajones, y contribuye a trascender la tesis "de ciertos discursos académicos y políticos, según la cual, con el fin de las administraciones coloniales y la formación de los Estados-nación en la periferia, vivimos ahora en un mundo descolonizado y poscolonial". Para estos autores, a lo que asistimos es "a una transición del colonialismo moderno a la colonialidad global, proceso que ciertamente ha transformado las formas de dominación desplegadas por la modernidad, pero no la estructura de las relaciones centro-periferia a escala mundial".

El postulado central que sostiene al enfoque decolonial es planteado por Mignolo (2007b, p. 26) en estos términos:

Si la colonialdad es constitutiva de la modernidad, puesto que la retórica salvacionista de la modernidad presupone ya la lógica opresiva y condenatoria de la colonialidad (de ahí los damnés de Fanon), esa lógica opresiva produce una energía de descontento, de desconfianza, de desprendimiento entre quienes reaccionan ante la violencia imperial. Esa energía se traduce en proyectos decoloniales que, en 
última instancia, también son constitutivos de la modernidad. La modernidad es una hidra de tres cabezas, aunque sólo muestra una: la retórica de salvación y progreso.

La noción de colonialidad tendría una mayor riqueza epistemológica, histórica y cultural para abordar el problema colonial, toda vez que "indica el espacio de análisis y los proyectos dirigidos a revelar la lógica oculta de la colonialidad (de manera semejante a los análisis de Marx para descubrir la lógica del capital)"; desde este punto de vista, se reafirman aquellos cuestionamientos que se le hacen al enfoque poscolonial, cuando se lo restringe a las líneas de investigación derivadas de los primeros estudios centrados en las experiencias del la India Británica -su sello de fábrica-, olvidando que "el concepto de poscolonialidad no es un significante vacío que integra la multiplicidad, sino que esconde, bajo el mismo signo, la diversidad de significantes llenos, llenos de diversas historias coloniales (hispánica, británica, francesa, estadounidense, etc.)" (Mignolo, 2011, p. 23).

Así, la colonialidad, que se manifiesta en los dominios del poder, del saber y del ser, constituye el gran aporte de la perspectiva decolonial para un estudio más situado de la cuestión colonial, y de la modernidad occidental como gran marco histórico e ideológico, toda vez que nos proporciona elementos "de explicación crítica de condiciones socio-culturales y económicas en América Latina, surgido de una reflexión localizada y distante de ser una importación de conocimiento" (Garbe y Quintero, 2014, párr. 14).
Para Mignolo (2007a), modernidad y colonialidad constituyen expresiones de un fenómeno que no se puede dividir ni comprender de manera aislada, salvo que en su fragmentación operen o actúen intencionalidades vinculadas a la dominación. Al respecto, explica:

Es conveniente considerar la modernidad/colonialidad como dos caras de una misma moneda y no como dos formas de pensamiento separados: no se puede ser moderno sin ser colonial, y si uno se encuentra en el extremos del espectro, debe negociar con la modernidad, pues es imposible pasarla por alto. La idea de América no puede separarse de la colonialidad: el continente en su totalidad surgió como tal, en la conciencia europea, como una gran extensión de tierra de la que había que apropiarse y un pueblo que había que evangelizar y explotar. (p. 32)

La singularidad de América, dice Mignolo (2007a, 70), "reside en los diversos borramientos que acompañaron la expansión colonial europea", lo que, además del genocidio, implicó la invisibilización, la marginación y el anulamiento epistemológico de los saberes, las historias, las experiencias, los imaginarios y las formas de organización de los grupos indígenas, de las poblaciones africanas que llegaron a estas tierras como víctimas de la muy moderna empresa del esclavismo europeo, de los pueblos trasplantados -al decir de Darcy Ribeiro- al sur del continente para blanquear la población y resguardar la pureza de la raza. Y agrega:

América es singular porque allí se establecieron las primeras estructuras de colonialismo interno del mundo 
moderno/colonial. ... La lógica de la colonialidad ha sido la responsable del establecimiento y conservación del sistema jerárquico en todas las esferas de la sociedad y de la eliminación de las economías que habían existido antes en el territorio que luego se convertiría en América. ... La matriz colonial de poder, aún hoy invisible a causa del triunfo de la retórica de la modernidad y la modernización, es precisamente la capacidad del sistema de reducir las diferencias a la inexistencia y hacer una categorización racial que convierte las vidas (humanas) en entidades prescindibles. Adoptar la americanidad significa vivir en medio de los borramientos de la colonialidad. (Mignolo, 2007a, p. 71)

Nos parece claro, a la luz de lo hasta aquí expuesto, que los borramientos de la modernidad, o más específicamente, del "patrón moderno-colonial de poder" (Quijano, 2014, p. 285), adquieren en nuestro continente un espesor diferente, singular, porque lo que hoy conocemos como nuestra América - siguiendo la feliz expresión martiana- fue el espacio originario de la expansión imperial/colonial, que no solo sometió por medio de la violencia a los sujetos individuales y colectivos (colonialidad del ser), sino que, además, mediante la imposición del eurocentrismo (colonialidad del saber) les negó "la posibilidad de razón, de pensamiento y de pensar futuro" (Mignolo, 2007a, p. 20). Es decir, llevó la negación de su humanidad hasta el límite del exterminio.

\section{IV.}

Los enfoques poscolonial y decolonial no son necesarimente incompatibles, antes bien, conviene comprenderlos en su complementariedad y reconocer sus diferencias. Ambos comparten elementos comunes, por ejemplo, la crítica "al desarrollismo, a las formas eurocéntricas de conocimiento, a la desigualdad entre los géneros, a las jerarquías raciales y a los procesos culturales/ideológicos que favorecen la subordinación de la periferia en el sistema-mundo capitalista"; además, comparten la crítica radical a las "ideologías desarrollistas europeas" y a los discursos “del 'orientalismo' y el 'occidentalismo' que han postulado a los pueblos no-europeos como los 'otros' inferiores". Sin embargo, discrepan en los énfasis: "mientras que la crítica de los postcolonial studies hace énfasis en el discurso colonial, el enfoque del sistema-mundo señala la interminable e incesante acumulación de capital a escala mundial como la determinación en última instancia", y mientras "las críticas poscoloniales enfatizan la agencia cultural de los sujetos, el enfoque del sistema-mundo hace énfasis en las estructuras económicas" (Castro-Gómez y Grosfoguel, 2007, pp. 13-15).

En cualquier caso, resulta evidente que la crítica sistemática y profunda de la modernidad occidental y su patrón de poder, que acabó por consolidar -por todos los medios y con pocos escrúpulos- la "expansión de las ideas e instituciones occidentales" (Mignolo, 2007a, p. 28), es la piedra de toque del análisis de la cuestión colonial, especialmente para una región como América Latina.

Así, por ejemplo, en uno de los pasajes de la novela El siglo de las luces, del cubano Alejo Carpentier, podemos encontrar una lectura del problema de la modernidad y su 
presencia en la cultura latinoamericana que nos ayuda a ilustrar nuestra línea argumentativa. Se trata de la llegada a la isla caribeña de Guadalupe, directamente desde la Francia revolucionaria de Robespierre, del texto del Decreto del 16 Pluvioso que proclamaba la abolición de la esclavitud y la igualdad de derechos, sin distinción de raza ni estado -principios emancipadores de la modernidad-, otorgado a todos los ciudadanos insulares. Pero el Decreto no llegaba solo. Al frente de esta travesía transoceánica aparecía el comerciante francés, masón y de conocimientos enciclopédicos, Víctor Hugues, "luciendo todos los distintivos de su Autoridad, inmóvil, pétreo, con la mano derecha apoyada en los montantes de la Máquina", cuyo retrato el autor envuelve en una alegoría: "con la Libertad, llegaba la primera guillotina al Nuevo Mundo" (Carpentier, 1988, p. 134).

Carpentier elaboró aquí una alusión profunda, una metáfora del engarce entre la trayectoria histórica de Europa y de América Latina, en tiempos y relaciones desiguales, con matices distintivos en cada caso, pero que desde entonces permanecerán indisolublemente unidas en sus contradicciones y paradojas, en sus encuentros y desencuentros. La ley y la máquina, el orden y progreso, se anunciaban como instrumentos de liberación en nuestras tierras. Pero, simultáneamente, sometidos al ideal civilizatorio moderno europeo, esos instrumentos trocarían, más tarde, en portadores de la opresión y del derramamiento de sangre de todas aquellas personas que se opusieran a la nueva forma de organización de la sociedad que imponía Occidente. De tal suerte, Víctor Hugues, el arquetipo del hombre moderno, se convierte en el precursor literario y ficticio de los muy reales Sarmiento que aparecerían luego en las tierras americanas. La guillotina, la Máquina, acompañaba y precedía a los derechos humanos en América Latina, como mucho antes el genocidio de los pueblos originarios cometido por los Cortés, Pizarro o Pedrarias Dávila, sellaba para siempre el crimen sobre el que se levantaría la civilización americana.

La modernidad occidental, con todo el esplendor de sus promesas de redención universal, entraba definitivamente en América durante el siglo de las luces. Pero esta región del mundo ya había sido incorporada a ese movimiento político, filosófico, comercial y cultural europeo, que destruía, poco a poco, los pilares del antiguo régimen, derribando a los dioses y la tradición de los tronos, e instaurando a la razón y al sujeto autónomo - eje de la subjetividad moderna- al frente de las nacientes repúblicas (Cancino, 2003): tres siglos antes de la Revolución Francesa, período histórico en el que Carpentier contextualiza su obra, desde el otro lado de la mar océano, la civilización europea ya se había abatido sobre las tierras recién descubiertas y en proceso de conquista, descargando sobre ellas "la explosión creadora del Renacimiento: América aparecía como una invención más, incorporada junto con la pólvora, la imprenta, el papel y la brújula al bullente nacimiento de la Edad Moderna" (Galeano 1971, p. 25).

El proceso de conquista y colonización otorgó a los vencedores ese singular derecho de invención y de posesión, que determinaría la forma subordinada, periférica, en que el llamado Nuevo Mundo, 
el hogar de los vencidos, sería incorporado a la modernidad occidental. Como lo explica Larraín (1996):

Nos convertimos en el otro de su propia identidad, pero fuimos mantenidos deliberadamente aparte de sus principales procesos por el poder colonial. Abrazamos con entusiasmo la modernidad ilustrada al independizarnos de España, pero más en su horizonte formal, cultural y discursivo que en la práctica institucional política y económica, donde por mucho tiempo se mantuvieron estructuras tradicionales $\mathrm{y} / \mathrm{o}$ excluyentes. (pp. 313-314)

La condición subalterna de América Latina en la modernidad occidental se concretó en dos dimensiones: una material, afincada en la imposición de la administración real española/portuguesa y la implantación del modo de producción hacia afuera, es decir, la extracción de materias primas y productos agrícolas para satisfacer las demandas de los mercados europeos, a partir de la explotación intensiva - e inhumana- de las poblaciones indígenas y grupos esclavos africanos empleados como mano de obra (que, en sus rasgos más generales, es la modalidad de desarrollo dominante hasta nuestros días, interrumpido solamente por algunas experiencias de desarrollo hacia adentro y de desconexión de los centros hegemónicos, ensayadas en la segunda mitad del siglo XX, y que tienen a la Revolución Cubana como su principal exponente).

La otra dimensión es la que corresponde a la esfera simbólica, en el contexto de un modelo de organización de la sociedad que encontraba (y todavía las busca) sus fuentes de legitimación -y de emulación- jurídica, política y especialmente cultural, en la tradición europea, y no en la tradición de los pueblos originarios del continente, o de los que surgieron del mestizaje y la convivencia en nuestras tierras de pueblos con distintas matrices culturales. Como lo explica Ortiz (1995, p. 19), en América Latina retomar el ideal de la modernidad representa, desde entonces, una de las maneras predilectas de las elites y algunas vanguardias "para ajustar nuestro reloj al tiempo de las exigencias universales".

Este desfase entre los tiempos de la modernidad a uno y otro lado del Atlántico, o de los confusos reflejos del espejo ajeno al que se miraban las emergentes naciones latinoamericanas, se pondría de manifiesto en el carácter limitado y concentrado de las diversas estrategias de modernización aplicadas en los últimos dos siglos. Por ejemplo, en la idea de homogenización de la cultura nacional (la identidad nacional), impulsada por los oligarcas liberales en el siglo XIX, y que implicaba la consolidación del Estado por la vía del mejoramiento de la raza, es decir, por medio de la nefasta empresa de reemplazar el legado cultural colonial, mestizo e indígena (Nahuelpán, 2007, pp. 161-162), para el incluir en su lugar el factor poblacional europeo, tal cual lo enunciara el ilustrado Sarmiento en su fórmula civilización o barbarie; idea que José Martí (en Hart-Dávalos, 2000, p. 205) impugnó en su ensayo Nuestra América, cuando sostuvo que "no hay batalla entre la civilización y la barbarie, sino entre la falsa erudición y la naturaleza".

Esta contradictoria y excluyente ruta modernizadora también se observa en la segunda mitad del siglo XX, con el auge y 
respaldo que las teorías de la industrialización y la modernización social encontraron en los gobiernos latinoamericanos, pero que tenían su asidero cultural en las ideas racionalistas y desarrollistas europeas y norteamericanas. Y más recientemente, el proyecto de avanzar hacia una modernización (la neoliberal), cuya referencia siempre gravita en lo externo, en otro lugar o en un futuro que jamás se alcanza, continúa imponiéndose con un acentuado sesgo proveniente del ideario y del imaginario cultural del neoliberalismo (Larraín, 1996).

El hecho de que el destino de los pueblos americanos en la modernidad se decidiera, primero, según el parecer de las cortes, las casas de contratación y los palacios cardenalicios, y más tarde, según su nivel de semejanza con el molde civilizatorio europeo o norteamericano, dejaría una impronta decisiva en la configuración de la cultura latinoamericana. Fundamentalmente, perfilaría nuestra trayectoria a la modernidad como un proceso y una experiencia de escisión, una construcción cultural fruto de un proceso conflictivo que estimulaba tanto la subordinación de las elites criollas y la oligarquía a los centros imperiales (políticos, económicos y culturales), como la resistencia de los grupos marginados.

Ese espacio fundamental de disputa entre lo hegemónico y lo contra-hegemónico, considera el filósofo y poeta Roberto Fernández Retamar (2004, p. 84), es el territorio en que palmo a palmo, frente a las pretensiones " de los conquistadores, de los oligarcas criollos, del imperialismo y sus amanuenses", ha ido forjándose nuestra genuina cultura - tomando este término en su amplia acepción histórica y antropológica"; allí donde se realiza la oposición de lo subalterno, del damné, frente a la ambición de los países capitalistas de englobar a nuestros pueblos en su proyecto civilizatorio, esa "versión moderna de la pretensión decimonónica de las clases criollas explotadoras".

Nuestra modernidad subordinada y eurocéntrica, tal cual la describiera Carpentier en su novela, tributaria de la lógica del orden, el progreso y la guillotina de Víctor Hugues, se expresa, entonces, en todas aquellas manifestaciones asociadas con el clientelismo político y cultural, el tradicionalismo ideológico, el autoritarismo que subsiste desde la colonia, el racismo encubierto, la falta de autonomía y desarrollo de la sociedad civil, la marginalidad y la economía informal, la fragilidad de las instituciones políticas y el encadenamiento de los países a una estrategia de desarrollo exógeno (Larraín, 1996); aspectos todos que no logra aprehender con claridad el análisis poscolonial, o cuando menos, se nos revela insuficiente. Siguiendo a Domingues $(2009,25)$, hacemos nuestra la idea de que "el pensamiento poscolonial reproduce mucho de lo que afirmaron las filosofías latinoamericanas pioneras de los años sesente y setenta, aunque esté más abierto que ellas al pluralismo de la vida social".

\section{V.}

Las preguntas sobre el impacto de la modernidad occidental y la colonialidad como fenómeno vigente y estructurante de relaciones de poder no son exclusivas de los enfoques poscolonial y decolonial. Tampoco han sido ajenas a la intelectualidad de 
nuestra región, a su búsquedas y empeños creadores. Más aún, podemos rastrear la trayectoria latinoamericana de estas inquietudes, en sus orígenes y diversas aproximaciones, en tres textos imprescindibles del pensamiento crítico de la región: la Carta de Jamaica de Simón Bolívar, de 1815; el ensayo Nuestra América, del prócer cubano José Martí; y la Segunda Declaración de La Habana, pronunciada en 1962 por Fidel Castro en una magna asamblea popular en la Plaza de la Revolución; una tríada insoslayable para la comprensión de las raíces históricas profundas de los procesos políticos y culturales de nuestra región.

Con sus particulares contextos y circunstancias de producción y circulación, escritos uno desde el exilio de Bolívar, otro desde la itinerancia en la que Martí empujó la lucha por la independencia de Cuba, y el último desde la ebullición revolucionaria que recorría toda América Latina y el mundo a inicios de la década de 1960, tiempos en los que Fidel despuntaba ya como referente mundial, estos documentos entretejen elementos comunes que van dando forma tanto a una identidad política y cultural que bien podemos llamar nuestroamericana, como a una problematización original, propia, de la cuestión colonial.

Asumiendo como principio epistemológico el a priori ontológico que sugiere Arturo Roig (2009), esto es, el poner nuestros seres mismos como valiosos, como sujetos protagonistas con voz, cuerpo y pensamiento propios, esta perspectiva nuestroamericana logra articular dimensiones específicas de la historia, la política, la cultura y las problemáticas sociales y económicas latinoamericanas, que dota de contenido teórico y metodológico un enfoque de análisis de nuestras realidades diversas que no pierde vigencia y que, por el contrario, nutre las fuentes del pensar y el hacer críticos desde el siglo XIX hasta el presente.

En la Carta de Jamaica, Bolívar expone de modo brillante un agudo análisis de la situación de la América meridional, en el que se advierten elementos de una lectura anticolonial y una naciente conciencia de nuestra particularidad en el proceso expansión de la modernidad occidental, precisamente en un momento -las primeras décadas del siglo XIX- en el que el sistema-mundo se encaminaba ya al ascenso hegemónico de las potencias noratlánticas frente a las ibéricas, y en el que, además, entraban en tensión y conflicto el viejo sistema colonial español con los incipientes desarrollos imperialistas en Gran Bretaña, primero, y en los Estados Unidos algunas décadas más tarde. En medio de ese mundo agitado, escribe Bolívar (2015, p. 94):

Nosotros somos un pequeño género humano; poseemos un mundo aparte, cercado por dilatados mares, nuevo en casi todas la artes y ciencias, aunque en cierto modo viejo en los usos de la sociedad civil. ... no somos indios ni europeos, sino una especie media entre los legítimos propietarios del país y los usurpadores españoles: en suma, siendo nosotros americanos por nacimiento y nuestros derechos los de Europa, tenemos que disputar éstos a los del país y mantenernos en él contra la invasión de los invasores; así nos hallamos en el caso más extraordinario y complicado.

En Nuestra América, Martí (en Hart-Dávalos, 2000, pp. 204-205) incorpora una 
crítica sobre el problema de la organización política de las repúblicas latinoamericanas y la cuestión nacional - desde su categoría de patria-, que hasta entonces había sido desdeñada por las élites criollas, ya fueran conservadoras o liberales, más interesadas en copiar, sin más, modelos ajenos a nuestra realidad, lo que no es sino otra expresión de la colonialidad del poder y del saber. El problema de nuestros pueblos, sostiene en su ensayo, pasaba por la negativa a construir y asumir métodos e instituciones propias, "nacidas del país mismo", que permitieran avanzar hacia el bienestar común de las mayorías, "aquel estado apetecible donde cada hombre se conoce y ejerce, y disfrutan todos de la abundancia que la Naturaleza puso para todos en el pueblo que fecundan con su trabajo y defienden con sus vidas". El buen gobernante en América, afirma, "no es el que sabe cómo se gobierna el alemán o el francés, sino el que sabe con qué elementos está hecho su país, y cómo puede ir guiándolos en junto". Martí también trató en ese texto el tema de la identidad cultural, que desde el siglo XIX y bajo la influencia del eurocentrismo que delineó la mentalidad colonial de nuestras élites, se asumió desde el falso dilema de civilización y barbarie. Su impugnación, vigorosa y contundente, es también un alegato a favor de la necesidad de forjar un pensamiento propio y de aprender a vernos con nuestros propios ojos: "No hay bata1la entre la civilización y la barbarie, sino entre la falsa erudición y la naturaleza" (en Hart-Dávalos, 2000, 205).

Finalmente, la Segunda Declaración de La Habana retoma las tesis anticolonialistas $\mathrm{y}$ antiimperialistas bolivarianas $\mathrm{y}$ martianas, ahora con la evidencia dolorosa y sangrienta de las huellas dejadas por el imperialismo estadounidense en nuestra América, desde la intervención en Cuba en 1897 y hasta la caída de Jacobo Árbenz en Guatemala, en 1954. El antiimperialismo se nos presenta aquí como bandera de lucha de los pueblos oprimidos de todo el planeta: “¿Qué es la historia de América Latina sino la historia de Asia, África y Oceanía? ¿Y qué es la historia de todos estos pueblos sino la historia de la explotación más despiadada y cruel del imperialismo en el mundo entero?" (Castro, 2009, p. 64), preguntó Fidel a su auditorio de más de un millón de personas. Y acto seguido respondió:

Cuba y América Latina forman parte del mundo. Nuestros problemas forman parte de los problemas que se engendran de la crisis general del imperialismo y la lucha de los pueblos subyugados; el choque entre el mundo que nace y el mundo que muere (Castro, 2009, p. 66).

En su alocución, el líder cubano, que ciertamente habla para su pueblo, pero que además sabe de la trascendencia histórica del acto y que sus palabras se unirán a la tradición emancipatoria nuestroamericana de dos siglos, incorpora a la matriz de análisis iniciada por Bolívar otro temas, entre ellos la soberanía, la autodeterminación, la liberación nacional (de los viejos y nuevos colonialismos) y la democracia popular. Y lo hace partiendo del protagonismo que, en adelante, tendrán en esas luchas los sujetos sociales que se perfilan como actores del nuevo tiempo (permítasenos citar en extenso): 
Con esta humanidad trabajadora, con estos explotados infrahumanos, paupérrimos, manejados por los métodos de fuete y mayoral, no se ha contado o se ha contado poco. Desde los albores de la independencia sus destinos han sido los mismos: indios, gauchos, mestizos, zambos, cuarterones, blancos sin bienes ni rentas, toda esa masa humana que se formó en las filas de la "patria" que nunca disfrutó, que cayó por millones, que fue despedazada, que ganó la independencia de su metrópoli para la burguesía; esa, que fue desterrada de los repartos, siguió ocupando el último escalafón de los beneficios sociales, siguió muriendo de hambre, de enfermedades curables, de desatención, porque para ella nunca alcanzaron los bienes salvadores: el simple pan, la cama de un hospital, la medicina que salva, la mano que ayuda.

Pero la hora de su reivindicación, la hora que ella misma se ha elegido, la vienen señalando con precisión ahora también de un extremo a otro del continente. Ahora, esta masa anónima, esta América de color, sombría, taciturna, que canta en todo el continente con una misma tristeza y desengaño, ahora esta masa es la que empieza a entrar definitivamente en su propia historia, la empieza a escribir con su sangre, la empieza a sufrir y a morir. Porque ahora, por los campos y las montañas de América, por las faldas de sus sierras, por sus llanuras y sus selvas, entre la soledad, o en el tráfico de las ciudades, o en las costas de los grandes océanos y ríos, se empieza a estremecer este mundo lleno de razones, con los puños calientes de deseos de morir por lo suyo, de conquistar sus derechos casi 500 años burlados por unos y por otros. Ahora, sí, la historia tendrá que contar con los pobres de América, con los explotados y vilipendiados de América Latina, que han decidido empezar a escribir ellos mismos, para siempre, su historia (Castro, 2009, p. 86).

Como puede apreciarse, una de las particularidades de nuestra historia, y que ha definido buena parte de los rasgos culturales de América Latina, ha sido la necesidad, a través de los siglos, de sobrevivir, luchar y resistir las múltiples formas de opresión y dominación de los colonialismos y de los imperios modernos: primero España, luego Gran Bretaña y más tarde Estados Unidos. Al pensarnos en relación con ellos, también hemos definido los ricos y diversos caminos de nuestra independencia siempre por alcanzar, la segunda y definitiva. Una independencia que no es solamente política o económica, sino que nos interpela en el ámbito mayor de la cultura y del pensamiento. Tal es le hilo conductor que entrelaza las ideas, las utopías y las luchas Bolívar, Martí y Castro, a quienes nos hemos acercado aquí, pero que también están presentes en el legado de numerosas mujeres y hombres que pueblan la historia emancipatoria de nuestra América.

Ese legado, que sigue siendo materia del presente, demuestra que la resistencia y la apropiación crítica de los principios emancipadores de la modernidad son signos de identidad de nuestra relación conflictiva con la cuestión colonial. Como dice Domigues (2009, 235-236), el imaginario de la modernidad occidental "encuentra aquí formas creativas que, en lo referente a las configuraciones institucionales internas, como a la propia inserción global de América Latina, avanzan para ampliar 
y actualizar sus horizontes axiológicos y normativos en una dirección emancipatoria, individual y colectiva".

\section{VI.}

En La expresión americana, el escritor cubano José Lezama Lima (2001, p. 63) caracteriza así lo que considera es el complejo terrible del americano:

Creer que su expresión no es forma alcanzada, sino problematismo, cosa a resolver. Sudoroso e inhibido por tan presuntuosos complejos, busca en la autoctonía el lujo que se le negaba, y acorralado entre esa pequeñez y el espejismo de las realizaciones europeas, revisa sus datos, pero ha olvidado lo esencial, que el plasma de su autoctonía, es tierra igual que la de Europa. Y que las agujas para el rayo de nuestros palacios, se hacen de síntesis, como la de los artesanos occidentales, y que hincan, como el fervor de aquellos hombres, las espaldas de un celeste animal, igualmente desconocido y extraño. Lo único que crea cultura es el paisaje y eso lo tenemos de maestra monstruosidad, sin que nos recorra el cansancio de los crepúsculos críticos.

No hay camino para desenrredarnos de la madeja de los complejos y la pequeñez inculcada por la tradición eurocéntrica de más de cinco siglos de negación de nosotros mismos, que no pase por el imperativo de la emancipación mental de nuestros pueblos, frente al persistente yugo de la colonialidad moderno/occidental.

Sólo así podremos desprendernos del velo excluyente de la modernidad, que nos impide ver y reconocer las historias y las experiencias, como las nuestras, que no han sido admitidas con estatuto de validez en la historia de Occidente, convirtiéndise en "el sello distintivo de la historia intelectual y de sus consecuencias éticas, políticas y económicas” (Mignolo, 2007a, p. 34).

Volver a las ideas fundacionales y a los desarrollos de nuestro pensamiento crítico, para confrontar sus desafíos teóricos y epistemológicos con la praxis política contemporánea, es ruta ineludible para los latinoamericanos y latinoamericanas del siglo XXI. Bien decía, ese sentido, el filósofo argentino Arturo Roig (2009, p. 147):
América Latina sólo se justificará en cuanto inicie desde sí misma un proce- so de humanización que sea conscien- te de las limitaciones de los anteriores procesos similares, y solo podrá hacerlo volviendo a todos aquellos legados que ha recibido, como asimismo a todos los que habrá de recibir, asumidos desde el sujeto latinoamericano concreto.

Dentro de la academia o fuera de ella, con el prisma poscolonial o el decolonial, consideramos que hoy nuestro principal reto es del conocer, restituir y valorizar la presencia del sujeto oprimido y subordinado -hombres y mujeres, niños y niñas y personas adultas mayores de todos los orígenes-, y de su cultura de resistencia que ha sido perenne obstáculo para los modernizadores (neo)coloniales, lo que hace de América Latina, todavía, un desafío a la modernidad occidental hegemónica.

Una tierra donde, al decir de FernándezRetamar (2004, 85), "la cultura gestada por el pueblo mestizo, esos descendientes de indios, de negros y de europeos", la 
cultura de las clases explotadas, de la pequeña burguesía, del campesinado pobre, de la clase obrera, y en definitiva, "la cultura de las masas hambrientas de indios, de campesinos sin tierra, de obreros explotados ..., de los intelectuales honestos y brillantes que tanto abundan en nuestras sufridas tierras", insiste en mirar y construir una sociedad distinta, con más democracia, más justicia social, más libertad y con derechos humanos, sociales, culturales y ambientales plenos.

En la contracara de la colonialidad, se gesta otra cultura contestataria que lucha por la liberación: es la cultura que se busca a sí misma más allá del dictum de integrarse o desaparecer; la que se niega a ser Europa o Estados Unidos, porque conoce como nadie las cicatrices que eso ha dejado en la historia de nuestra América. Es, en suma, la cultura latinoamericana que intenta mirarse más allá de las imposturas modernas o de las trampas que provoca el reflejo distorsionado de nuestro rostro en el espejo de lo ajeno.

\section{Referencias}

Bolívar, S. (2015). Simón Bolívar, escritos anticolonialistas (selección de Gustavo Pereira). Caracas: Fundación Editorial El perro y la rana.

Carpentier, A. (1988). El siglo de las luces. Barcelona: Editorial Seix Barral.

Cancino, H. (2003). Modernidad y tradición en el pensamiento latinoamericano en los siglos XIX y XX. Sociedad y discurso, 3, 1-33.
Castro-Gómez, S. y Grosfoguel, R. (compiladores). (2007). El giro decolonial: Reflexiones para una diversidad epistémica más allá del capitalismo global. Bogotá: Siglo del Hombre Editores; Universidad Central, Instituto de Estudios Sociales Contemporáneos y Pontificia Universidad Javeriana, Instituto Pensar.

Coronil, F. (2000). Naturaleza del poscolonialismo: Del eurocentrismo al globocentrismo. En E. Lander (Comp.), La colonialidad del saber: Eurocentrismo y ciencias sociales. Buenos Aires: CLACSO.

Domingues, J. (2009). La modernidad contemporánea en América Latina. Buenos Aires: CLACSO / Siglo XXI Editores.

Galeano, E. (1971). Las venas abiertas de América Latina. México D.F.: Siglo XXI.

Garbe, S. y Quintero, P. (16 de noviembre de 2004). El proyecto modernidad/ colonial. Una aproximación desde la diferencia de la teoría poscolonial. Ojalá - Revista en la diáspora. Recuperado de http://ojal.de/politik/ el-proyecto-modernidadcolonialidad-una-aproximacion-desde-la-diferencia-de-la-teoria-postcolonialdas-projekt-modernitatkolonialitateine-annaherung-aus-der-differenzzur-postkolonialen-theorie/

García-Márquez, G. (1982). La soledad de América Latina. Recuperado de https://sophie.unam.mx/sites/default/files/ggm-la-soledad-de-al.pdf 
Hall, S. (2008). ¿Cuándo fue lo poscolonial? Pensar al límite. En S. Mezzadra (Comp.), Estudios poscoloniales. Ensayos fundamentales. Madrid: Traficantes de Sueños.

Larraín, J. (1996). La trayectoria latinoamericana a la modernidad. Revista Estudios Públicos, 66, 313-333.

Lezama, J. (2001). La expresión americana. México, D.F.: Fondo de Cultura Económica.

Martí, J. (2000a). Nuestra América (1891). En A. Hart Dávalos (Ed.), José Martí y el equilibrio del mundo. México D.F.: Fondo de Cultura Económica.

Martí, J. (2000b). El tercer año del Partido Revolucionario Cubano. En A. Hart Dávalos (Ed.), José Martí y el equilibrio del mundo. México D.F.: Fondo de Cultura Económica.

Mezzadra, S. (Comp.). (2008). Estudios poscoloniales. Ensayos fundamentales. Madrid: Traficantes de Sueños.

Mignolo, W. (2007a). La idea de América Latina. La herida colonial y la opción decolonial. Barcelona: Editorial Gedisa.

Mignolo, W. (2007b). El pensamiento decolonial: Desprendimiento y apertura. En S. Castro-Gómez, y R. Grosfoguel (Comp.), El giro decolonial: Reflexiones para una diversidad epistémica más allá del capitalismo global. Bogotá: Siglo del Hombre Editores; Universidad Central, Instituto de Estudios Sociales Contemporáneos y Pontificia Universidad Javeriana, Instituto Pensar.
Mignolo, W. (2011). Historias locales / diseños globales. Colonialidad, conocimientos subalternos y pensamiento fronterizo. Sevilla: Ediciones Akal.

Nahuelpán, H. (2007). El sueño de la identidad latinoamericana o la búsqueda de lo propio en lo ajeno. Atenea, 495, 157-164.

Ortiz, R. (1995). Cultura, modernidad e identidades. Nueva Sociedad, 137, 17-23.

Quijano, A. (2014). Cuestiones y horizontes. Antología esencial. Buenos Aires: CLACSO.

Roig, A. (2009). Teoría y crítica del pensamiento latinoamericanos. Buenos Aires: Una Ventana.

Santos, B. (2009). Una epistemología del Sur. México, D.F.: Siglo XXI / CLACSO.

Shohat, E. (2008). Notas sobre lo postcolonial. En S. Mezzadra (Comp.), Estudios poscoloniales. Ensayos fundamentales. Madrid: Traficantes de Sueños.

Spivak, G. (2015). Crítica de la razón poscolonial. Hacia una historia del presente evanescente. Madrid: Ediciones Akal. 